\title{
HISTOCHEMICAL OBSERVATIONS ON THE LIPID CHANGES IN THE RAT CORPUS LUTEUM DURING VARIOUS REPRODUCTIVE STATES
}

\author{
S. S. GURAYA \\ Department of Zoology, College of Basic Sciences and Humanities, \\ Punjab Agricultural University, Ludhiana, Punjab, India
}

(Received 7th May 1974)

\begin{abstract}
Summary. A histochemical study has been made of lipid changes in rat CL during the oestrous cycle, pseudopregnancy, pregnancy and lactation. The possible physiological significance of these lipid changes in relation to steroid biosynthesis has been discussed.
\end{abstract}

\section{INTRODUGTION}

A consistent sequence of lipid changes has been shown to occur in a variety of species during the transformation of granulosa to luteal cells (Guraya, 1973). The most important histochemical change is the development of abundant diffuse lipoproteins throughout the cytoplasm and the accumulation of some lipid droplets consisting mainly of phospholipids. The appearance of diffuse lipoproteins may serve as a useful histochemical indicator of the process of luteinization that occurs in response to vascularization and LH. From these observations, it has been suggested (Guraya, 1971, 1973) that the diffuse lipoproteins and the lipid droplets are intimately connected with steroidogenesis.

The present histochemical study was undertaken to examine the lipid changes in rat CL during the oestrous cycle, pseudopregnancy, pregnancy and lactation to extend those of Everett $(1945,1947)$.

\section{Animals}

\section{MATERIALS AND METHODS}

Female Holtzman rats, weighing 255 to $300 \mathrm{~g}$, were kept in an air-conditioned room with a controlled lighting regimen of $14 \mathrm{hr}$ light $/ 10 \mathrm{hr}$ dark. They were maintained on Purina laboratory rat chow supplemented with carrots and water. Vaginal smears were examined each morning. Rats showing regular 4- or 5-day oestrous cycles were used and histochemical analysis of the lipids in the CL was performed at all stages of the reproductive cycle.

Six rats were killed on each day of the oestrous cycle and both ovaries were fixed. Pseudopregnancy, which lasted 12 to 14 days, was induced by mating with a vasectomized male on the day of vaginal cornification, which was designated Day 0. Four rats were killed on each day of pseudopregnancy. Four rats were killed on each day of pregnancy, Day 1 being the day on which spermatozoa were found in the vaginal lavage. The day of parturition was 
designated Day 1 and four females were killed on each day of lactation until Day 16.

\section{Histochemical procedures}

Details of the fixing fluids and histochemical techniques used have been reported in previous papers (Guraya, 1968a, b). Frozen sections of fixed and postchromed ovaries were cut at 8 to $10 \mu \mathrm{m}$ on a freezing microtome and were then submitted to various histochemical tests for lipids. Sudanophilic lipids, which stained pink in Nile Blue and red in red Sudan dyes, together with negative reactions in the material extracted with cold acetone, were interpreted as neutral fats (triglycerides). Acidic lipids (phospholipids), lipoproteins and proteins generally stain blue in Nile blue. Only those sudanophilic substances which stained blue in Nile blue and blue-black in acid haematein, together with negative reactions in the material treated with cold ethanol and hot pyridine, were assumed to contain acidic lipids (phospholipids). Those substances, which stained blue-green with the Schultz test, followed by a negative reaction in the material extracted with cold acetone, were considered to be cholesterol and/or its esters.

\section{RESULTS}

The conspicuous lipid changes shown in the rat CL during the oestrous cycle, pseudopregnancy, pregnancy and lactation are summarized in Table 1.

\section{Oestrous cycle}

Metoestrus. The CL of metoestrous rats showed the same histochemical features as those described in detail for the 1-day-old CL of the rabbit (Guraya, 1968b). The vascularized granulosa lutein cells developed abundant diffuse lipoproteins throughout the cytoplasm and some lipid granules consisting of phospholipids; the large lipid droplets also showed some triglycerides. The theca interna cells could still be recognized at the periphery of the CL, although they had shrunk considerably. They were filled with coarse lipid bodies which also showed Schultz-positive material (cholesterol and/or its esters), in addition to triglycerides and phospholipids.

Dioestrus. The histochemical features of CL during dioestrus were similar to those at metoestrus, except that theca interna cells with their lipid accumulations could not be distinguished and some granulosa lutein cells contained more lipid droplets. More triglycerides were present in some of these as judged from their pink staining in Nile blue and red colouring in red Sudan dyes. Cholesterol and/or its esters demonstrable with the Schultz test were still not visible in any part of the CL. The diffuse lipoproteins did not show any visible change.

Pro-oestrus. The main histochemical features of luteal cells during pro-oestrus remained the same as those described for the earlier stages, but the initiation of storage of cholesterol and/or its esters was observed in some large lipid droplets; this change was more conspicuous in the luteal cells of central regions of the CL. 


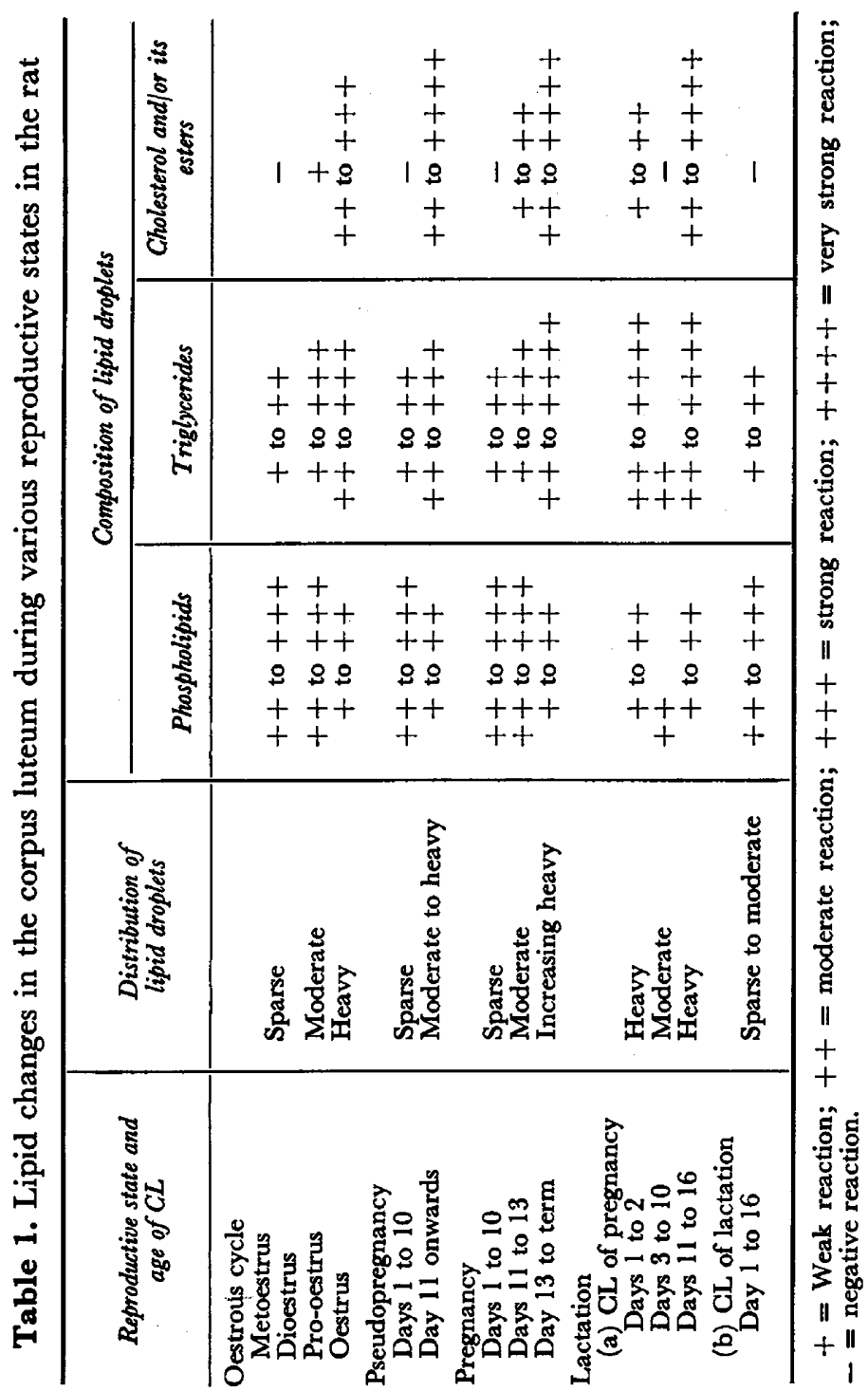


Oestrus. After ovulation, the CL from the previous cycle ( 4 to 5 days old) contained increasing numbers of lipid droplets in most of which cholesterol and/or its esters were present. No visible change could be demonstrated in the diffuse lipoproteins. The CL became relatively less vascular and more fibrous. The involuting CL during the subsequent cycles showed storage of more cholesterol and/or its esters and triglycerides; the diffuse lipids began to disappear and pigments started to appear in the luteal cells.

\section{Pseudopregnancy}

The 1- to 10-day-old CL of pseudopregnancy showed the same histochemical features as those described for metoestrus and dioestrus, but the luteal cells were larger and contained fewer lipid droplets but more diffuse lipoproteins. In the 8- to 10-day-old CL, the luteal cells contained increasing numbers of lipid droplets which consisted of phospholipids and triglycerides. From Day 10 onwards, the amount of large lipid droplets increased faster, and cholesterol and/or its esters besides the triglycerides and phospholipids was stored. On Days 12 and 13, the amount of cholesterol-positive lipid droplets was greatly increased.

\section{Pregnancy}

From Day 1 to Day 10, the CL of pregnancy were histochemically similar to those of metoestrus, dioestrus and early pseudopregnancy. The wellvascularized luteal cells showed abundant diffuse lipoproteins but only a few lipid granules which consisted mainly of phospholipids. The coarse lipid droplets contained some triglycerides. Schultz-positive material (cholesterol and/or its esters) was not seen.

Between Days 11 and 13, usually on Day 12, the luteal cells contained increasing numbers of lipid droplets in some of which cholesterol and/or its esters were also present. From Day 12 onwards, the lipid droplets consisted mainly of cholesterol and/or its esters, and the content of triglycerides and some phospholipids showed a progressive increase. From Day 17 to Day 22, when the female was approaching term, the histochemical reactions for cholesterol and/or its esters and triglycerides became very strong. These lipid changes during the later stages of pregnancy were accompanied by decreasing vascularity.

\section{Lactation}

In the rat, the $\mathrm{CL}$ of lactation are formed following post-partum ovulation. Two sets of CL, one belonging to pregnancy and the second to lactation, are present.

After parturition, the cholesterol and/or its esters which had accumulated in the CL during the second half of gestation began to disappear. The depletion was apparently completed on Days 1 and 2 as no Schultz-positive material was seen in the persisting CL of gestation on Day 3 after parturition, but diffuse lipoproteins and lipid droplets consisting mainly of phospholipids and triglycerides were still present. Some luteal cells contained relatively more lipid droplets. From Day 11 to Day 13, the CL of gestation again started 
to store cholesterol and/or its esters, and triglycerides, and became more fibrous and less vascular.

The vascular CL of lactation contained diffuse lipoproteins throughout the cytoplasm but only a few lipid granules were present, consisting mainly of phospholipids and very few triglycerides. Schultz-positive material (cholesterol and/or its esters) was not seen.

\section{DISGUSSION}

The present histochemical studies agree well with biochemical studies on the

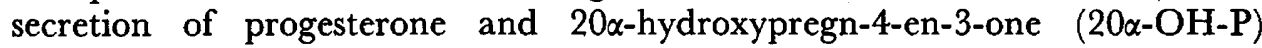
(Eto, Masuda, Suzuki \& Hosi, 1962; Telegdy \& Endroczi, 1963; Fajer \& Barraclough, 1967; Yoshinaga, Grieves \& Short, 1967; Hashimoto, Henricks, Anderson \& Melampy, 1968; Chatterton, Macdonald \& Greep, 1968; Hashimoto \& Wiest, 1969; Uchida, Masumikado \& Tamotsu, 1969; Roser \& Bloch, 1972). The diffuse lipoproteins are presumed to derive from the abundant membranes of smooth reticulum, act as a site for enzymes involved in steroidogenesis and may also serve as a reservoir for the storage of hormone precursors (Flint \& Armstrong, 1972; Armstrong \& Flint, 1973). Active synthesis of a steroid hormone through stimulation by gonadotrophin is thought to occur only when there is no storage of cholesterol and/or its esters (Guraya, 1971, 1973).

It is assumed, therefore, that in 1- to 2-day-old CL during the oestrous cycle of the rat, the granulosa lutein cells which do not show cholesterol and/or its esters must be secreting steroid hormones. The highest progesterone output occurs on Day 2 when the luteal cells also do not appear to contain cholesterol and/or its esters. From their observations of the morphology of the Golgi apparatus, McDonald, Seiki, Prizant \& Goldfien (1969) attributed the secretion of high levels of progesterone to the luteinized granulosa cells during dioestrus because the thecal cells degenerate and disappear from view. This is also in agreement with the present observations. The appearance of increasing numbers of lipid droplets consisting mainly of cholesterol and/or its esters and triglycerides in the granulosa luteal cells during pro-oestrus and oestrus suggests that they begin to function in the storage of hormone precursor. The availability of preformed sterol precursors for progestin synthesis is greater in ovaries at pro-oestrus and oestrus than in those at metoestrus or dioestrus (Chatterton et al., 1968). The storage of hormone precursor also correlates well with the falling levels of progestins in the ovarian vein during pro-oestrus and oestrus (Hashimoto et al., 1968), the increased activity of hydrolytic enzymes (Lobel, Rosenbaum \& Deane, 1961), the fragmentation and degeneration of the Golgi apparatus (McDonald et al., 1969), and the appearance of 20 $\alpha$-hydroxysteroid dehydrogenase (Balogh, 1964; Pupkin, Bratt, Weisz \& Lloyd, 1966; Turolla, Magrini \& Gaetani, 1966). Everett (1945) suggested that old CL may be reactivated during pro-oestrus. He found that luteal cell lipid increased in late dioestrus but then decreased markedly, though transiently, during pro-oestrus. Such a decrease in lipids has not been observed in the present strain of rat. 
The ultrastructural data of Long (1973) and the presence of abundant diffuse lipoproteins and the absence of cholesterol and/or its esters in 1- to 11-day-old CL of pseudopregnancy and pregnancy suggest that the CL are capable of secreting progestins. This correlates well with the increasing levels of progesterone in the ovarian venous blood during pseudopregnancy and the first half of pregnancy (Hashimoto et al., 1968; Wiest, Kidwell \& Balogh, 1968; Hashimoto \& Wiest, 1969; Wiest, 1970; Uchida, Kadowaki, Nomora, Miyata \& Miyake, 1970; Morishige, Pepe \& Rothchild, 1973). The increasing numbers of lipid droplets consisting of cholesterol and/or its esters, triglycerides and some phospholipids in the luteal cells of pseudopregnancy and pregnancy after Days 11 and 12 suggests that the cells begin to store hormone precursor progressively more during the second half of pregnancy. This also agrees with the falling levels of progesterone during the second half of pregnancy (Eto et al., 1962; Fajer \& Barraclough, 1967; Hashimoto et al., 1968; Wiest et al., 1968; Wiest, 1970). The accumulation of abundant cholesterol- and triglyceridecontaining lipid droplets in the luteal cells from Days 17 to 22 also correlates well with the very low levels of progesterone and high levels of $20 \alpha-\mathrm{OH}-\mathrm{P}$ (see Madhwa Raj \& Moudgal, 1970) and the activity of $20 \alpha-\mathrm{OH}-\mathrm{SDH}$ in the luteal cells of late pregnancy (Days 19 to 21) has been shown to increase (Wiest et al., 1968). The association of abundant cholesterol- and triglyceridecontaining lipid droplets with low levels of progesterone secretion during the second half of pregnancy suggests a weak gonadotrophic stimulation and it is of interest that $\mathrm{LH}$ levels during the last 7 days of pregnancy are not measurable (see Madhwa Raj \& Moudgal, 1970).

The depletion of lipid droplets in the CL of pregnancy during the first 2 days of lactation suggests the occurrence of strong gonadotrophic stimulation, as a result of suckling. This extensive mobilization of preformed cholesterol may be related to the increased output of progestins. The depletion of similar lipid droplets from the ovarian interstitial gland cells of the rabbit has been correlated with an increased output of progestins (Guraya, 1973). These findings lend further support to the suggestion that lipid droplet accumulation during the second half of pregnancy in the rat and weak gonadotrophic stimulation are associated. The storage of cholesterol and/or its esters, in the CL of pregnancy on Day 12 of lactation indicates that they again become relatively inactive in the secretion of steroid hormones, while the CL of lactation apparently continue to produce steroid hormones. From the absence of storage of cholesterol and/or its esters in both sets of CL up to Day 12 of lactation, it can be suggested that their function must be the secretion of steroid hormones rather than the storage of hormone precursor. This suggestion is strongly supported by the fact that a high progesterone and a low $20 \alpha-\mathrm{OH}-\mathrm{P}$ secretion pattern has been found in post-partum or lactating rats (Eto et al., 1962; Grota \& Eik-Nes, 1967; Wiest et al., 1968).

\section{REFERENCES}

Armstrong, D. T. \& Flint, A. P. F. (1973) Isolation and properties of cholesterol ester-storage granules. Biochem. F. 134, 399. 
BALOGH, K. (1964) A histochemical method for the demonstration of $20 \alpha$-hydroxysteroid dehydrogenase activity in rat ovaries. F. Histochem. Cytochem. 12, 670.

Chatterton, R. T., Jr, Macdonald, G. J. \& Greep, R. O. (1968) Biosynthesis of progesterone and $20 \alpha$-hydroxypregn-4-en-3-one by the rat ovary during the estrous cycle and early pregnancy. Endocrinology, 83, 1-10.

Eto, T., Masuda, H., Suzuki, T. \& Host., T. (1962) Progesterone and pregn-4-ene-20 $\alpha$-ol-3-one in rat ovarian venous blood at different stages of reproductive cycle. Jap. F. anim. Reprod. 8, 34.

Everetr, J. W. (1945) The microscopically demonstrable lipids of cyclic corpora lutea in the rat. Am. F. Anat. 77, 292.

Everetr, J. W. (1947) Hormonal factors responsible for deposition of cholesterol in the corpus luteum of the rat. Endocrinology, 41, 364-377.

Fajer, A. B. \& Barraclough, C. A. (1967) Ovarian secretion of progesterone and 20 $\alpha$-hydroxypregn4-en-3-one during pseudopregnancy and pregnancy in rats. Endocrinology, 81, 617-622.

Flint, A. P. F. \& Armstrong, D. T. (1972) Dynamic aspects of ovarian cholesterol metabolism: regulation by gonadotropins. In Gonadotropins, Chap. 22. Eds. B. B. Saxena, G. G. Beling and H. M. Gandy. Wiley, New York.

Grota, L. J. \& EIK-Nes, K. B. (1967) Plasma progesterone concentrations during pregnancy and lactation in the rat. F. Reprod. Fert. 13, 83-91.

GURAYA, S. S. (1968a) Histochemical observations on the granulosa and theca interna during follicular development and corpus luteum formation and regression in the American opossum. F. Endocr. 40, $237-241$.

GuRAYA, S. S. (1968b) A histochemical study of preovulatory and postovulatory follicles in the rabbit ovary. F. Reprod. Fert. 15, 381-387.

Guraya, S. S. (1971) Morphology, histochemistry and biochemistry of human ovarian compartments and steroid hormone synthesis. Physiol. Rev. 51, 785.

Guraya, S. S. (1973) Interstitial gland tissue of mammalian ovary. Acta endocr., Copenh., Suppl. 171, 1-27.

Hashimoto, I., Henricks, D. M., Anderson, L. L. \& Melampy, R. M. (1968) Progesterone and pregn4-en-20 $\alpha$-ol-3-one in ovarian venous blood during various reproductive states in the rat. Endocrinology, 82, 333-341.

Hashimoto, I. \& Wiest, W. G. (1969) Correlation of the secretion of ovarian steroids with function of a single generation of corpora lutea in the immature rat. Endocrinology, 84, 873-885.

Lobel, B., Rosenbaum, R. M. \& Deane, H. W. (1961) Enzymic correlates of physiological regression of follicles and corpora lutea in the ovaries of normal rats. Endocrinology, 68, 232-247.

LoNG, J. A. (1973) Corpus luteum of pregnancy in the rat-ultrastructural and cytochemical observations. Biol. Reprod. 8, 87-99.

MaDonald, D. M., Seiki, K., Prizant, M. \& Goldfien, A. (1969) Ovarian secretion of progesterone in relation to the Golgi apparatus in lutein cells during the estrous cycle of the rat. Endocrinology, 85, 236-243.

Madhwa RAJ, H. G. \& Moudgal, N. R. (1970) Hormonal control of gestation in the intact rat. Endocrinology, 86, 874-889.

Morishige, W. K., Pepe, G. J. \& Rothchild, I. (1973) Serum luteinizing hormone, prolactin and progesterone levels during pregnancy in the rat. Endocrinology, 92, 1527-1530.

Pupkin, M., BRatt, H., Weisz, J., Lloyd, G. W. \& Balogh, K., JR (1966) Dehydrogenases in the ovary. I. A histochemical study of $\Delta^{5}-3 \beta$ - and $20 \alpha$-hydroxysteroid dehydrogenases and enzymes of carbohydrate oxidation during the estrous cycle. Endocrinology, 79, 316-327.

Roser, S. \& BLOCH, R. B. (1972) Comparison of the variations of ovarian progesterone during 4 and 5 day cycles in the rat. C. r. Séanc. Soc. Biol. 165, 1995.

Telegdy, G. \& Endroczi, E. (1963) The ovarian secretion of progesterone and $20 \alpha$-hydroxypregn-4en-3-one in rats during the estrous cycle. Steroids, 2, 119.

Turolla, E., Magrini, U. \& Gaetani, M. (1966) Histochemistry of ovarian $20 \alpha$-hydroxysteroid dehydrogenase in the rat during the estrus cycle. Experientia, 22, 675.

Uchida, K., Kadowaki, M., Nomora, Y., Mryata, K. \& Miyake, T. (1970) Relationship between ovarian progestin secretion and corpora lutea function in pregnant rats. Endocr. Fap. 17, 499.

Uchida, K., Masumikado, W. \& Tamotsu, M. (1969) Ovarian secretion of progesterone and 20 $\alpha$ hydroxypregn-4-en-3-one during rat estrus cycle in chronological relation to pituitary release of luteinizing hormone. Endocr. Jap. 16, 227.

Wiest, W. G. (1970) Progesterone and 20 $\alpha$-hydroxypregn-4-en-3-one in plasma, ovaries and uteri during pregnancy in the rat. Endocrinology, 87, 43-48.

Wiest, W. G., Kidwell, W. R. \& BaloGh, K., JR (1968) Progesterone catabolism in the rat ovary: a regulatory mechanism for progestational potency during pregnancy. Endocrinology, 82, 844-859.

Yoshinaga, K., Grieves, S. A. \& SHORT, R. V. (1967) Steroidogenic effects of luteinizing hormone and prolactin on the rat ovary in vivo. F. Endocr. 38, 423-430. 